\title{
Mobile Assessment Procedures for Mental Health and Literacy Skills in Education
}

\author{
https://doi.org/10.3991/ijim.v12i3.8038 \\ Agathi Stathopoulou( $\left.{ }^{(}\right)$ \\ Center for Diagnosis, Differentiation and Support, Athens, Greece \\ agathi.stathopoulou@yahoo.com \\ Zoe Karabatzaki \\ Ministry of Education, Athens, Greece \\ Georgia Kokkalia, Eleni Dimitriou, Paraskevi Ioanna Loukeri \\ National Center for Scientific Research "Demokritos", Agia Paraskevi, Attica, Greece \\ Alexandra Economou \\ University of Athens, Athens, Greece \\ Athanasios Drigas \\ National Center for Scientific Research "Demokritos", Agia Paraskevi, Attica, Greece
}

\begin{abstract}
Mobile technology seems crucial for learning and teaching as it plays an important role in student's social, emotional and academic life. This paper examines its role in secondary education focusing in mobile applications that support literacy and mental health in students. The results of a research that investigated the relationship between performance in language of secondary school pupils and the occurrence of depression symptoms are presented.
\end{abstract}

Keywords-mobile technology, secondary education, literacy, mental health

\section{Introduction}

Mobile technologies are playing an increasingly important role in pupil's social, emotional and academic live. Devices such as smartphones, tablets, and e-book readers connect them with the world instantly, heightening access to information, enabling interactivity with others and enhancing also their learning and knowledge. Applications that run on these devices let users not only consume but also discover and produce important works and projects. Mobile technologies and networks are increasingly expanding in their sophistication and capacity, while new applications (software programs) are enhancing the ways in which students learn, talk, feel and interact. As a result, new technology is used to teach and to enhance the teaching of specific areas [1]. 
According to existing studies, mobile devices are one of the most successful technologies for learning, as they are quite attainable and easy to be used mainly by learners who have learning difficulties. Mobile device, which is considered as a handheld, is a pint-sized computing device and very often goes with a touch or non-touch display screen and other times with a mini keyboard. Additionally, there are different types of mobile devices, as the mobile phones, smart phones, PDAs, pagers and Personal Navigation Devices. PDAs and smart phones are considered the most common mobile devices, which offer all the advantages of a personal computer. Also, their use gives greater feedback for educators and has a supportive role for learner as the provision of a necessary basis like telecommunication equipment and perfect training content are thought significant for attaining the educational goals [2].

The arrival of Mobile Learning (ML) came with the invention of portable technologies and mobile devices in the 1970s and 1980s while they gave important changes and revolutions with the rapid development of modern science and technology. Mobile devices such as cell phones, personal digital assistants and smart phones are offering powerful functions, as do the personal computers. Because these devices are small, smart, portable, and comfortable to use, particularly to the digital natives, all these devices are regarded as teaching tools in the ML [3].

Furthermore, mobile learning (ML) has increasingly attracted the interest of educators, specialists, and companies that design learning systems as this technology provides the eventual of collaborative interaction and learning opportunities for different types of learners. Although mobile learning is currently applied in small-scale projects, is thought useful in more educational settings. As a result, mobile telephones do not require technological training, do not intimidate users, and remain a friendly tool in classrooms, especially for the children [4]. There are many examples of ways in which children can learn efficiently using the mobile technology while it provides them with different ways of relating their physical experiences to abstract knowledge, from playing around to understanding what the world is. They also increase children's opportunities to make connections between their observations and ideas that can help them understand difficult concepts [5]. Moreover, an advantage of learning while a child use a mobile device is that children become more motivated and engaged than when staring at a PC, but more significantly, mobile learning gives opportunities for ways in which children can learn. Taking the above into consideration, researchers believe that children who use mobile learning can make more connections between their ideas and prior knowledge, while they may start to view and understand the world differently. This progress in educational technology represents a major topic in the way computers can be used to change children's minds. Notable to these ideas is the belief that mobile technologies can be designed to enable children to move in and out of physical, digital, and communicative spaces. This mobility can be achieved individually or as a whole classroom with teachers, parents and specialists. Finally, it is assumed that mobile technologies help children to make connections between what they are observing, collecting, accessing, and thinking over time, place, and people while they are assessed in many educational areas [6].

Moreover, the present generation of pupils is growing up with information and communication technology (ICT) embedded in their daily lives. Such pupils handle 
digital information on a daily basis, are connected to each other via mobile technologies, work interactively, often perform several tasks more or less simultaneously and play mobile games to a greater extent than previous generations [7]. The use of mobile games in education may be an excellent way to combine situated and active learning with fun. The learning potential of mobile and location based technologies lies in the possibility to embed learning in an authentic environment, enhance engagement and foster learning outside traditional formal educational settings. In education, there have been reached many studies that support the view that properly designed digital educational activities can become an important tool for efficient and effective learning especially in the area of the literacy skills. A wide variety of mobile multimedia applications have been accepted as developmentally suitable education resources for children's spoken and written language development. Research has also shown that children who do not have a good start in literacy development by the time they reach school rarely learn to read on time and still face difficulties in the elementary school. As a result, early intervention during the preschool years is crucial not only for children who are at risk of facing learning difficulties in the elementary school but also for children of different ages [8].

In addition, supporters have seen the integration of handheld computers as a way to enhance student learning and achievement. Evidence of classes' handhelds use in such curriculum areas as reading, mathematics, social studies and science prove promising practices in this domain [9]. As PDA's, cell phones and mp3 players have converged and altered into more sophisticated mobile devices, the iPod Touch has appeared as a pocket computer with many and different classroom possibilities. The iPod Touch and the iPhone as well, are equipped to carry out a multitude of complex tasks, many of which can be used especially in the domain of the literacy skills. These devices are inexpensive, compared to classroom laptop or computer labs, and their portability and durability provide students with potential learning tools that meet the classroom and the home [10].

Furthermore, the introduction of mobile computing devices (personal digital assistants [PDAs], followed by smartphones and tablet computers) has also, greatly impacted medical fields, including medicine and mental health. Health care professionals now use smartphone or tablet computers for functions they used to need a pager, cellphone, and PDA to accomplish. Smartphones and tablets combine both computing and communication features in a single device that can be held in a hand or stored in a pocket, allowing easy access and use at the point of care and health. In addition to voice and text, new mobile device models offer more advanced features, such as web searching, global positioning systems (GPS), high-quality cameras, and sound recorders. Without a doubt, medicine, care and mental health are some of the disciplines that have been profoundly affected by the availability of mobile devices and this is evident in many surveys that reveal a high ownership rate of these tools, in both clinical practice education and treatment. Specifically, the results of a similar study found that $85 \%$ of respondents, respectively, use mobile devices in a wide variety of clinical settings ranging from classrooms to hospitals [11].

Mobile health (mHealth) technologies have experienced a recent surge in attention because of their potential to transform the delivery of health care. This enthusiasm is 
partly due to the near ubiquity of smartphones and tablets among clinicians, as well as to the stream of mobile medical apps and devices being created. Mobile devices can become an ideal platform for self-monitoring symptoms and behaviors and providing personalized feedback, motivational support, and psychotherapeutic advice. They can also be used for educational and training purposes or for administering standardized assessments and calculating scores [12]. Previous research suggests that mental health interventions delivered through mobile apps can have positive effects on a range of mental health problems, such as depression, stress, anxiety, and smoking cessation. These apps can be used as stand-alone self-help programs or in conjunction with guided programs offered via a website or through direct contact with a mental health professional. They can act as a bridge between therapy sessions and have the potential to improve adherence to treatment and mainly there is a growing amount of mental health apps for mobile devices that are youth-friendly, easily accessible and flexible to use [13].

Under the light of the above statements, in this article we will try to present some of the most important mobile applications that are used for children with limited literacy skills and who might face mental problems such as depression. The most significant mobile procedures in the above domains (literacy and mental health) are going to be discussed briefly presenting the role that mobile learning play in education and in health. Additionally, some significant mobile applications in secondary education are going to be viewed briefly, while, the results of a specific study that investigated the relationship between performance in language of secondary school pupils and the occurrence of depression symptoms are going to be discussed.

\section{Mobile technologies for mental health-depression}

Research shows that the majority of people and particularly young people with mental health problems often do not seek professional help, despite the existence of effective psychological and pharmacological treatments [14]. However, mobile technologies, social networks and online media present an exciting, untapped opportunity for engaging younger populations in health and wellness activities, as well as promoting universal prevention and intervention. Given the widespread use of smartphones and the increasing uptake of tablet devices, the use of mobile and wireless technologies for health objectives is believed to have the potential to improve the cost and quality of health care received, as well as reduce stigma and increase treatment accessibility globally. Since the creation of Apple's iTunes App Store and Google's Android Market that allowed users to download mobile application, more and more sophisticated mobile apps are being developed in the field of mental health, and are being adopted almost as quickly as they can be developed [15].

Moreover, mobile devices can become an ideal platform for self-monitoring symptoms and behaviors and providing personalized feedback, motivational support, and psychotherapeutic advice. They can also be used for educational and training purposes or for administering standardized assessments and calculating scores. Previous research suggests that mental health interventions delivered through mobile apps can 
have positive effects on a range of mental health problems, such as depression, stress, anxiety, and smoking cessation These apps can be used as stand-alone self-help programs or in conjunction with guided programs offered via a website or through direct contact with a mental health professional. As a result, these procedures can act as a bridge between therapy sessions and have the potential to improve adherence to treatment [16].

Furthermore, there is a growing amount of mental health apps for mobile devices that are youth-friendly, easily accessible and flexible to use. Firstly, Mobile Therapy is an app where users can indicate their current mood at random times throughout the day, as well as record their energy levels, sleep patterns, activities and eating habits. The app offers therapeutic exercises ranging from breathing visualizations, to progressive muscle relaxation, to useful ways to disengage from a stressful situation. The information can later be charted and printed out so that users can evaluate the connection between their mood and other factors in their lives [17].

Additionally, another application the MyCompass [18] is a self-guided psychological treatment delivered via mobile phone and computer, designed to reduce mild-tomoderate depression, anxiety and stress, and improve work and social functioning. It encourages real-time self-monitoring of moods, mood triggers, and lifestyle behaviors using SMS text messaging and email prompts and shows significant results for the users.

Other mobile procedures such as the Cognitive Control App was designed as a video game that modulates cognitive control abilities, a common neurological deficit seen in depression. The app uses adaptive algorithms to adjust the intervention's difficulty to the user's level of proficiency over time [19]. Also, the Problem-Solving Therapy App (iPST) that is based on problem-solving therapy focuses on a 7-step model to manage mood. In this app, participants choose a goal and are guided through a 7-step process to create an action plan. Problem-solving therapy is an evidencebased treatment and is particularly effective in treating depression. Additionally, the Information Control (Health Tips) is an app that provides daily health tips for improved health, such as self-care (e. g, taking a shower) or physical activity (e.g., taking a walk). Although it provides daily advice on improving one's health, it is not tied to any specific theory, similar to supportive control treatments [20]. Furthermore, another application such as the ReliefLink is a mood-tracking tool that tweets users regular affirmations, helps them make a safety plan and puts them it touch with nearby resources if they're contemplating suicide, while the Live Happy app that is based on positive psychology provides a set of daily activities scientifically proven to boost both short and long term happiness [21].

Lastly, even though the use of technology in mental health is relatively new, the idea of using games to help children and adults with mental health problems is not novel. There are hundreds of mental health apps already on the market, and many incorporate elements of gamification (the use of video game techniques for more than entertainment purposes). Researchers have often focused on using these techniques with children, however, now it is common between them to play games on their phones. For example Personal Zen is an app based on a cognitive treatment for anxiety called attention-bias modification training. With the help of a game, children can 
learn to ignore threatening stimuli and focus on the good, feeling that way less anxious in stressful situations [22].

\section{$3 \quad$ Mobile technologies for assessing literacy skills}

Language and literacy learning has undergone rapid changes over the past several years, from computer-assisted learning to the more recent mobile-device-assisted learning and recent years, a large body of literature has documented attempts to develop alternative learning tools for computer- assisted learning. The emergence of wireless technology and a variety of mobile-device innovations has received a great deal of attention in the field of education while, mobile devices offer features of portability, social connectivity, context sensitivity, and individuality, which desktop computers might not offer [23]. Mobile devices have made learning movable, real-time, collaborative, and seamless [24] and the use of these devices may be called "mobile learning" in general. Mobile devices allow users to share information, collaborate, and communicate with others with ease, either synchronously or asynchronously. Researchers have applied the social connectivity/interaction feature of mobile devices to language leaning thus the features of shared tasks and real time interaction not only enhance the efficiency of group learning, but also improve the quality of interaction during language learning [25].

In the light of the above view, Mobile Learning (ML) has increasingly attracted the interest of educators, researchers, and companies that develop educational systems and publish learning materials. This kind of technology provides the potential for collaborative interaction and learning opportunities for all people [26]. Mobile Learning is potentially useful in more educational settings as do not require technological training, do not intimidate users, and remain unobtrusive in classrooms [27]. In addition to constituting a new technology, mobile learning implies a new methodology that asks plenty of things, from the design of new didactic resources adjusted to the terminals and mobility, to the pedagogical principles that exist behind them [28].

Taking the above into account, Fernandez- Lopez et al. [29] developed a platform called Picca, for children with educational literacy needs. The designers made a mobile platform based on iPad and iPod touch devices, in order to cover the main ideas of the learning process, which are the preparation, use and the evaluation. This platform includes four kinds of educational activities, which can be used by teachers depending on children needs. The results of their experiment shows that the use of the Picca is associated with positive effects in the development of learning skills for children who have special educational needs, claiming that the basic skills have been improved. Besides, in many cases children have the opportunity to perform activities that previously were not accessible to them, as the interface and the contents of the activities have been designed in order to be appropriate to them. The study also suggests that the type of activities provided is developmentally appropriate for learning purposes as well as the use of electronic devices and multimedia contents increases children's interest in learning and attention. 
In addition, children who often struggle to communicate and talk with ease educational communicative tools can enable them to get their needs met, to socialize, and learn [30]. According to a study, Mocotos, a new class of mobile communication tool includes a portable device not much larger than popular cell phone where both children and adults can use for interaction activities. Teachers and specialists may program the devices while the primary interface metaphor consists of virtual cards. The Mocoto comes preinstalled with a comprehensive library of cards and users can also add custom cards to the interface by taking pictures, scanning in materials, or creating other images. Each card includes both a name and other information that is needed, which enable the categorization, searching and management of the cards. The type of the tool is to provide a rich interface for various programming and customization activities. Furthermore, the device itself is then reserved for rapid access to the library of virtual cards and supports pre-planning as well as the daily activities that occur in all classrooms. The program is flexible enough to present multiple functions supported by different devices inside the classroom besides the use of custom audio cues for the cards may support a variety of communication and learning activities from highly structured communication during an educational activity to unstructured impulsive words [31].

Furthermore, there is the general opinion that iPad applications are being used as an additional tool for learning within educational environments improving the academic skills of children. A recent pilot study investigated the efficacy of iPad applications in improving the literacy and overall academic skills in children. Results suggested that while statistical significance was not obtained, practical significance was found for the use of iPad applications to support learning in the literacy skill area of spelling knowledge and number concept. Also, the iPad applications that were chosen for this project were selected with several key criteria in mind and mainly focused on the key academic concepts. Besides, they were developmentally appropriate for children with several levels of difficulty through which children could move independently, according to their needs and they provided positive or neutral feedback to children's responses. For the intervention condition, the applications gave multiple opportunities for the child to learn about and practice at least one of the skill areas [32].

Moreover, speech and Language Therapy (SLT) is an area focused in the rehabilitation of people suffering from different kinds of disorders and disabilities related with language and communication. According to latest estimates of the World Health Organization, the most of countries do not have appropriate structures, and enough personnel and resources to provide healthcare and rehabilitation services to these persons. However, RAMSES is an intelligent environment that uses mobile devices and embedded electronic systems to provide support during the SLT process. Basically, RAMSES relies in a set of mobile applications, electronic devices, and on a robotic assistant consisting in two elements: a central processor and a displacement electronic platform performing several activities to children who need this kind of help. The use of this application seems to give promising results as help users to control their body, interact with others, reproduce words, expressions, songs etc., detect and recognize objects and perform visual, intellectual and motor simulation on different situations [33]. 


\section{Mobile applications for research purposes in secondary education}

Mobile devices such as smartphones are vastly gaining popularity due to their relatively strong computing capability built into small sizes, their Internet connectivity, the availability of various types and easy-to-use mobile software applications. Mobile technologies are now gaining increasing attention and popularity across educational research [34]. The popularity of mobile technologies among college students is increasing dramatically. In fact, the majority of students' smartphones and tablets are reportedly being used for academic purposes [35], [36], [37]. Furthermore, lately many educators in secondary schools emphasize the creative, student-centered pedagogical approaches facilitated by mobile apps, while others stress the role of online communication and collaboration in creating well-informed and well-connected global citizens [38], [39]. The latest generation of smart phones is tools for supporting learning — in and outside the classroom [40]. Mobile applications also have significant potential for use in literacy performance and in mental health interventions with adolescents [41], [42],[43].

Mobile applications are rapidly growing in importance and can be used for various purposes. They have been used widely and especially in educational research. One of the educational purposes for which mobile applications were be used was learning to read and pronounce the verses of the Holy Quran. There are applications that help users read the Quran, and search for a particular word or phrase in the text as well as listening to verses of the Holy Quran. Recent study aimed to reveal the relationship of behavioral factors and perceived usefulness of using the mobile to revel application "Say Quran" for studying the Quran on students' perceived performance, satisfaction and behavior [35]. In this research, students of the Islamic University had been asked to use the application to help them on studying the Quran. The results from this study provide evidence that there is a positive relationship between the mobile application "Say Quran" and students' perceived performance, satisfaction and behavior while engaged in studying the Holy Quran.

The Spanish National University of Distance Education published a study regarding the use of smartphones in higher education. The purpose of this trial was to assess the use of a specific didactic mobile application and the potential to enhance student learning in university subjects in ubiquitous environments and develop generic competencies according to the European Higher Education Field [44]. The main aim of the study was to reveal and assess students' perceptions regarding the capabilities of smartphones and apps in improving learning processes in university subjects were assessed. The conclusions indicate that the use of apps developed specifically for university subjects is highly valued by students as a new format which both supports and enhances learning practices which not only provide further opportunities to establish connections and relations with their subjects, but also foster collaborative work among students and professors.

Another study made an attempt to evaluate the impact of the Active Teen Leaders Avoiding Screen-time (ATLAS) intervention for adolescent boys, an obesity- prevention intervention using smartphone technology [43]. The benefits of mobile applica- 
tions appear in research in which language learners used mobile apps to profit from their available learning time outside the classroom. The results show that mobile applications provide insight in student perspectives of the benefits of using mobile apps for foreign language learning [45]. In addition, mobile applications have potential for helping people increase their physical activity, since little is known about the behavior change techniques via installed application, as recent research showed [46]. Even in psychological health research mobile apps have significant use. Study reports the research, results in which the installation of a specific application in a mobile phone provides a cognitive behavioral therapy intervention for the treatment of depression [47]. Lately there is an increasing number of mobile apps available for adolescents with mental health problems and an increasing interest in assimilating mobile health into mental health services. Researchers have systematically searched for relevant publications, which describe mental health apps (targeting depression, bipolar disorder, anxiety disorders, self-harm, suicide prevention, conduct disorder, eating disorders and body image issues, schizophrenia, psychosis, and insomnia) for mobile devices for use by adolescents younger than 18 years [48].

\section{$5 \quad$ Methodology of our research}

\subsection{Purpose of our research}

The aim of our study was to investigate the relationship between performance in language of secondary school pupils and the occurrence of depression symptoms.

\subsection{Main research question}

The main research question that we were concerned about was whether there is a relationship between the performance of secondary school students in the language lesson and the appearance of depression symptoms.

\subsection{Data Collection}

Questionnaire Youth Self Report [49] was the instrument used in collecting the data. In particular, the questions of subscales were about "anxiety/depression" and "withdrawal/depression. In addition to educators were given a small questionnaire on completing pupils' demographics and their performance in the language lesson.

\subsection{Participants}

The survey involved 160 pupils aged 12-17 years studying in Secondary General and Vocational Secondary Education Schools in Athens who came to Center of Assessment and Support due to their learning disabilities. For the same students, we received some information from a corresponding number (160) of educators (120 female-40 male). Of the pupils 101 were boys and 59 were girls. Three (3) pupils 
were 12 years old, 30 pupils were 13 years old, 28 were 14 years old, 34 were 15 years old, 46 were 16 years old and 19 were 17 years old. About the class they were attending, 24 pupils were in first grade, 27 pupils attending second grade, 23 pupils were studying at the third grade, 39 pupils were studying in the 1st Lyceum, 30 pupils were studying in the 2 st Lyceum and 17 pupils were studying in the 3 st Lyceum. Language evaluation in the Greek education system in secondary education varies between 0-20 points, with best performance the highest grade.

\subsection{Procedure}

We collected our data from October of 2016 to May of 2017 with 160 participants, who are language educators in secondary schools in Athens. Moreover, to each participant was given an Android-based cell phone with an online structured questionnaire developed by us. The sample size of this study was about 160 pupils. The questionnaire contained questions recording school performance in literacy, parent profession, and parent education. The pupils who participated had visited Center of Assessment and Support due to learning difficulties. The pupils in a special session completed the questionnaire Youth Self Report on a tablet that was available to them after their parent's permission.

\subsection{Statistical analysis}

Statistical analysis of the data was carried out with the SPSS 23 statistical package. The answers rates for Achenbach (2003) Youth Self-Referendum questionnaire and the frequency of pupils' grade in the language lesson were calculated. We found the Correlations of the questionnaire questions with the "performance in the language lesson" variable using the Pearson r Correlation Coefficient (two tailed). Our results are presented in the form of graphs and tables.

\subsection{Results}

Table 1. Percentages pupils' responses in the questionnaire Youth Self Report

\begin{tabular}{|l|c|c|c|}
\hline \multicolumn{1}{|c|}{ variables } & it does not fit & fits somewhat & fits a lot \\
\hline rejoices a little & 47,5 & 40,6 & 11,9 \\
\hline it cries a lot & 61,3 & 28,1 & 9,4 \\
\hline fears situations & 65 & 26,3 & 8,8 \\
\hline fears school & 87,5 & 10,6 & 1,9 \\
\hline afraid of doing something bad & 48,1 & 44,4 & 7,5 \\
\hline it must be perfect & 28,1 & 51,3 & 20,6 \\
\hline he feels he is not loved & 76,3 & 17,5 & 6,3 \\
\hline he feels unworthy & 61,3 & 31,3 & 7,5 \\
\hline he prefers on his own & 56,9 & 33,1 & 10 \\
\hline nervous & 34,4 & 43,1 & 21,9 \\
\hline
\end{tabular}




\begin{tabular}{|l|c|c|c|}
\hline afraid & 40 & 38,1 & 21,9 \\
\hline he feels very guilty & 71,9 & 20,6 & 6,9 \\
\hline he does not talk & 66,3 & 29,4 & 3,8 \\
\hline secretive & 39,4 & 48,8 & 11,9 \\
\hline embarrassed & 41,9 & 38,8 & 19,4 \\
\hline shy, cowardly & 49,4 & 43,1 & 6,9 \\
\hline talks about suicide & 85,6 & 13,8 & 0,6 \\
\hline without energy & 54,4 & 39,4 & 6,3 \\
\hline unhappy & 74,4 & 21,3 & 4,4 \\
\hline isolated & 73,8 & 23,1 & 3,1 \\
\hline is worried & 18,8 & 51,3 & 29,4 \\
\hline
\end{tabular}

In Figure 1 described the frequencies of pupils' performance in the language lesson.

\section{performance in the language lesson}

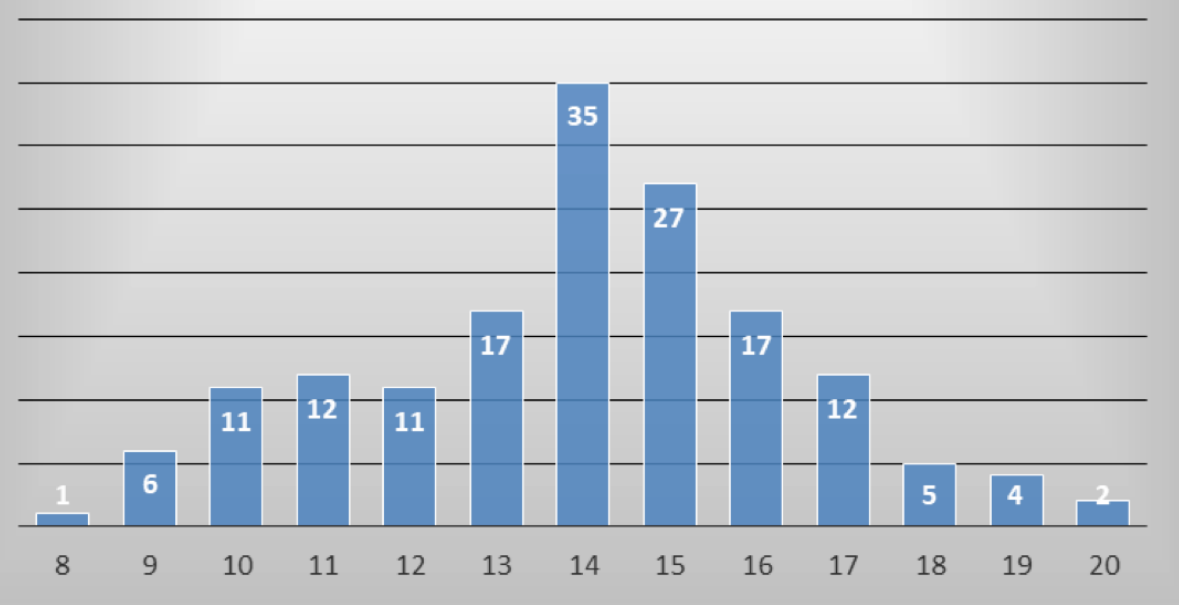

Fig. 1. Frequencies of pupils performance in the language lesson

\subsection{Correlations between the questions from the Youth Self Report} questionnaire and the variable 'performance in the language lesson'

The value of the Pearson Correlation Coefficient between the variable 'performance in the language lesson' and the summarized answers of the Youth Self-Report questionnaire for depression were statistically significant $(r=-0,236, p=0,003)$. Specifically, statistically significant was the value of the Pearson Correlation index between the variable 'performance in the language lesson' and the following individual variables of the Youth Self Report for depression: rejoices a little $(r=-0,281, p=0,000)$, he feels he is not loved $(r=-0,236, p=0,003)$ he feels unworthy $(r=-0,196, p=0,013)$, 
nervous $(\mathrm{r}-0,163, \mathrm{p}=0,039)$, shy, cowardly $(\mathrm{r}=-0,198, \mathrm{p}=0,012)$, unhappy $(\mathrm{r}=-0,223$, $\mathrm{p}=0,005)$, isolated $(\mathrm{r}=-0,219, \mathrm{p}=0,005)$. The negative values of the Correlation Coefficient of the variables mentioned show that students who have $\alpha$ low performance in the language lesson have more chances to develop depression symptoms or the reverse; students who develop depression symptoms have a low performance in the language lesson.

\section{Conclusion}

Over the last ten years, there has been a notable increase in the rise of applicationbased smartphone and tablet devices in everyday use. As such, smartphones and tablet devices have become ever more prevalent and now are considered as a necessary tool for educators, schools and students. The advancement of mobile and wireless communication technologies has encouraged an increasing number of studies concerning mobile learning, in which students are able to learn via mobile devices without being limited by space and time; in particular, the students can be situated in a real-world scenario associated with the learning content. Although such an approach seems interesting to the students, researchers have emphasized the need for well-designed learning support in order to improve the students' learning and mental achievements. Therefore, it has become an important issue to develop methodologies or tools to assist the students to learn in a mobile learning environment supporting as well their communication skills. Based on this perspective, this study tried to explore the role that mobile applications play in students' literacy and mental development investigating as well how mobile procedures may affect thus development. Furthermore, the results of our study that showed how mental health and literacy development is associated in Greek children in secondary education were investigated.

More specifically, although previous studies have suggested an association between depression and poor school performance measured by grade point average (GPA) or numerical evaluation of success on various courses [50], [51], [52], our research attempted to investigate the relationship between depressive symptoms and performance in the language lesson. In spite of the fact, that ambitious effort has been done in the search for the relationship between low school performance in the language course as a cause of depressive symptoms our study showed that risk for depression symptoms during adolescence was elevated in pupils with low performance in language lesson. Such results confirm the literature about the correlation of psychological problems in school performance and especially in performance of language lesson. Furthermore, the development of depression symptoms in adolescence is influenced by a complex interplay of biological, psychological, and environmental factors. Several psychosocial risk factors for depression symptoms have been identified, including negative life events, relationship difficulties, interpersonal skills deficits, and a cognitive style characterized by pessimistic attributions and expectations. Undoubtedly school is one of the most important environmental factors for the emergence of depression symptoms. Taking the above into account, several studies have evaluated the effectiveness of the problem solving to decrease the depressive symp- 
toms [53], [54]. In addition similar studies have revealed that people with depression symptoms exhibit social skills deficits in the domain of verbal behavior [55].

As a result, it is obvious that in all educational systems the language course especially in secondary education develops both life skills and problem solving. From the above is deducted that language is the pylon for developing solving problem skills and the basis for the thought and behavior [56]. Especially higher values in the responses «nervous», «afraid» and «is worried» indicate the direct relationship of depression symptoms with school performance. On he other hand, the role of the mobile technology is considered significant for educational purposes therefore, mobile and ubiquitous learning has become one of the main issues in the research community. Compared with traditional instruction or information from textbooks, mobile learning seems to be a more attractive way of learning that can trigger the interest and motivation of the learners while such procedures seem to have positive results in children's mental health.

\section{$7 \quad$ References}

[1] Chiong, C., \& Shuler, C. (2010). Learning: Is there an app for that. In Investigations of young children's usage and learning with mobile devices and apps. New York: The Joan Ganz Cooney Center at Sesame Workshop

[2] McManis, L. D., \& Gunnewig, S. B. (2012). Finding the education in educational technology with early learners. YC Young Children, 67(3), 14

[3] Goodwin, K. (2012). Use of tablet technology in the classroom. NSW Department of Education and Communities

[4] Uzunboylu, H., Cavus, N., \& Ercag, E. (2009). Using mobile learning to increase environmental awareness. Computers \& Education, 52(2), 381-389. https://doi.org/10.1016/ j.compedu.2008.09.008

[5] Sandvik, M., Smørdal, O., \& Østerud, S. (2012). Exploring iPads in practitioners' repertoires for language learning and literacy practices in kindergarten. Nordic Journal of Digital Literacy, 7(03), 204-221

[6] Powell, S. (2014). Choosing iPad apps with a purpose: Aligning skills and standards. Teaching Exceptional Children, 47(1), 20-26 https://doi.org/10.1177/0040059914542765

[7] Huizenga, J., Admiraal, W., Akkerman, S., \& Dam, G. T. (2009). Mobile game-based learning in secondary education: engagement, motivation and learning in a mobile city game. Journal of Computer Assisted Learning, 25(4), 332-344 https://doi.org/10.1111/ j.1365-2729.2009.00316.x

[8] Banister, S. (2010). Integrating the iPod Touch in K-12 education: Visions and vices. Computers in the Schools, 27(2), 121-131 https://doi.org/10.1080/07380561003801590

[9] Auchincloss, C., \& McIntyre, T. (2008). iPod "Teach": Increased access to technological learning supports through the use of the iPod Touch. Journal of Special Education Technology, 23(2), 45-49

[10] Shoemake, L. P. (2007). Handhelds for reading and note taking. Learning and Leading with Technology, 35(2), 36

[11] Payne, H. E., Lister, C., West, J. H., \& Bernhardt, J. M. (2015). Behavioral functionality of mobile apps in health interventions: a systematic review of the literature. JMIR mHealth and uHealth, 3(1) https://doi.org/10.2196/mhealth.3335 
[12] Donker, T., Petrie, K., Proudfoot, J., Clarke, J., Birch, M. R., \& Christensen, H. (2013). Smartphones for smarter delivery of mental health programs: a systematic review. Journal of medical Internet research, 15(11) https://doi.org/10.2196/jmir.2791

[13] Proudfoot, J., Clarke, J., Birch, M. R., Whitton, A. E., Parker, G., Manicavasagar, V., ... \& Hadzi-Pavlovic, D. (2013). Impact of a mobile phone and web program on symptom and functional outcomes for people with mild-to-moderate depression, anxiety and stress: a randomised controlled trial. BMC psychiatry, 13(1), 31.2. https://doi.org/10.1186/1471244X-13-312

[14] Hampton, K. (2004). Neighbourhoods and new technologies: connecting in the Network Society. Neighbourhoods and New Technologies, London, The Work Foundation.

[15] Hollis, C., Morriss, R., Martin, J., Amani, S., Cotton, R., Denis, M., \& Lewis, S. (2015). Technological innovations in mental healthcare: harnessing the digital revolution. The British Journal of Psychiatry, 206(4), 263-265. https://doi.org/10.1192/bjp.bp.113.142612

[16] Steinhubl, S. R., Muse, E. D., \& Topol, E. J. (2013). Can mobile health technologies transform health care? Jama, 310(22), 2395-2396. https://doi.org/10.1001/jama.2013.281078

[17] Kumar, S., Nilsen, W. J., Abernethy, A., Atienza, A., Patrick, K., Pavel, M., ... \& Hedeker, D. (2013). Mobile health technology evaluation: the mHealth evidence workshop. American journal of preventive medicine, 45(2), 228-236. https://doi.org/10.1016/ j.amepre.2013.03.017

[18] Harrison, V., Proudfoot, J., Wee, P. P., Parker, G., Pavlovic, D. H., \& Manicavasagar, V. (2011). Mobile mental health: review of the emerging field and proof of concept study. Journal of mental health, 20(6), 509-524. https://doi.org/10.3109/09638237.2011. $\underline{608746}$

[19] Ophir, E., Nass, C., \& Wagner, A. D. (2009). Cognitive control in media multitaskers. Proceedings of the National Academy of Sciences, 106(37), 15583-15587. https://doi.org/10.1073/pnas.0903620106

[20] Arean, P. A., Hallgren, K. A., Jordan, J. T., Gazzaley, A., Atkins, D. C., Heagerty, P. J., \& Anguera, J. A. (2016). The use and effectiveness of mobile apps for depression: results from a fully remote clinical trial. Journal of medical Internet research, 18(12). https://doi.org/10.2196/jmir.6482

[21] Larsen, J. L. S., Frandsen, H., \& Erlangsen, A. (2016). MYPLAN-A mobile phone application for supporting people at risk of suicide. Crisis.

[22] Iglesias Cancio, I. (2014). The application of gamification methodologies to e-learning contexts in order to enhance its student's performance, motivation, and collaboration (Master's thesis, Universitat Oberta de Catalunya).

[23] Chinnery, D. (2006). Low Power Design Automation, Ph. D. dissertation, Department of Electrical Engineering and Computer Sciences.

[24] Wong, L. H., \& Looi, C. K. (2011). What seams do we remove in mobile-assisted seamless learning? A critical review of the literature. Computers \& Education, 57(4), 23642381. https://doi.org/10.1016/j.compedu.2011.06.007

[25] Lan, Y. J., Sung, Y. T., \& Chang, K. E. (2007). A mobile-device-supported peer-assisted learning system for collaborative early EFL reading.

[26] Biström, J. (2005, April). Peer-to-peer networks as collaborative learning environments. In HUT T-110.551 seminar on internetworking.

[27] Cavus, N., \& Uzunboylu, H. (2009). Improving critical thinking skills in mobile learning. Procedia-Social and Behavioral Sciences, 1(1), 434-438. https://doi.org/10.1016/j.sb spro.2009.01.078 
[28] Prieto, J. C. S., Migueláñez, S. O., \& García-Peñalvo, F. J. (2013). Understanding mobile learning: devices, pedagogical implications and research lines. Education in the Knowledge Society, 15(1), 20.

[29] Fernández-Cavia, J., \& López, M. (2013). Communication, destination brands and mobile applications.

[30] Hayes, G. R., Gardere, L. M., Abowd, G. D., \& Truong, K. N. (2008, April). CareLog: a selective archiving tool for behavior management in schools. In Proceedings of the SIGCHI Conference on Human Factors in Computing Systems (pp. 685-694). ACM. https://doi.org/10.1145/1357054.1357164

[31] Monibi, M., \& Hayes, G. R. (2008, June). Mocotos: mobile communications tools for children with special needs. In Proceedings of the 7th international conference on Interaction design and children (pp. 121-124). ACM. https://doi.org/10.1145/1463689.1463736

[32] Hutchison, A., Beschorner, B., \& Schmidt-Crawford, D. (2012). Exploring the use of the iPad for literacy learning. The Reading Teacher, 66(1), 15-23. https://doi.org/10.1002/ TRTR.01090

[33] Robles-Bykbaev, V. E., Lopez-Nores, M., Pazos-Arias, J. J., \& Garcia-Duque, J. (2015, May). RAMSES: a robotic assistant and a mobile support environment for speech and language therapy. In Innovative Computing Technology (INTECH), 2015 Fifth International Conference on (pp. 1-4). IEEE.

[34] Hsu,Y., Rice, K.,Dawley, L. (2012). Empowering educators with Google's Android App Inventor: An online workshop in mobile app design. British Journal of Educational Technology, 43(1) pages E1-E5 https://doi.org/10.1111/j.1467-8535.2011.01241.x

[35] Alqahtani,M.,Mohammad,H.(2015) Mobile Applications' Impact on Student Performance and Satisfaction. The Turkish Online Journal of Educational Technology, volume 14 issue 4, pp.102-112

[36] Chen, B., \& Denoyelles, A. (2013). Exploring students' mobile learning practices in higher education. Educause Review, 7.

[37] Stockwell, G. (2007). Vocabulary on the move: investigating an intelligent mobile phonebased vocabulary tutor. Computer Assisted Language Learning, 20(4), pp 365 - 383 https://doi.org/10.1080/09588220701745817

[38] Chen,B.X. (2011). Always on: How the iPhone unlocked the anything-anytime-anywhere future - and locked us in. Cambridge, MA: Da Capo

[39] Pegrum,M.,Oakley,G.,Faulkne,R.(2013) Schools going mobile: A study of the adoption of mobile handheld technologies in Western Australian independent schools Australasian Journal of Educational Technology, 29(1) pp 66-81 https://doi.org/10.14742/ajet.64

[40] Schmiedl,G.,Grechenig,T.(2010) Mobile enabling of virtual teams in school: An observational study on smart phone application in secondary education. International Conference of Education Technology and Computer, 74-79 https://doi.org/10.1109/ICETC.2010. 5529432

[41] Kenny,R, Dooley, B.,Fitzgerald,A.(2016) Developing mental health mobile apps: Exploring adolescents' perspectives. Health informatics journal, Vol 22, Issue 2, pp. 265-275 https://doi.org/10.1177/1460458214555041

[42] Green,L.,S.,Hechter,R.P.,Tysinger,P.D.,Chassereau,K.D.(2014) Mobile app selection for 5th through 12th grade science:The development of the MASS rubric. Computers \& Education 75, pp 65-71 https://doi.org/10.1016/j.compedu.2014.02.007

[43] Smith, J.,J. Morgan,P., J.Plotnikoff, R., C.,Dally, K.,A., Salmon, J., Okely, A., D,. Finn, T., L, Lubans, D. R.(2014) Smart-Phone Obesity Prevention Trial for Adolescent Boys in Low-Income Communities: The ATLAS RCT, PEDIATRICS Volume 134, Number 3, pp 723-731 https://doi.org/10.1542/peds.2014-1012 
[44] Vazquez-Cano,E. (2014) Mobile Distance Learning with Smartphones and Apps in Higher Education, Educational Sciences: Theory \& Practice, 14(4), pp 1505-1520

[45] Steel,C. (2012) Fitting learning into life: Language students' perspectives on benefits of using mobile apps. In M. Brown, M. Hartnett \& T. Stewart (Eds.), Future challenges, sustainable futures. proceedings ascilite Wellington 2012. pp.875-880

[46] Conroy,D.,E.,Chih-HsiangYang,dJaclyn,P.(2014) Behavior Change Techniques in TopRanked Mobile Apps for Physical Activity, American Journal of Preventive Medicine, Volume 46, Issue 6, p. 649-652 https://doi.org/10.1016/j.amepre.2014.01.010

[47] Watts,S.,Mackenzie,A.,Thomas,C.,Griskaitis,A.,Mewton,L.,Williams,A, Andrews,G.(2013) CBT for depression: a pilot RCT comparing mobile phone vs. computer. BMC Psychiatry 13:49 https://doi.org/10.1186/1471-244X-13-49

[48] Grist, R., Porter, J.,Stallard, P ( 2017) Mental Health Mobile Apps for Preadolescents and Adolescents: A Systematic Review, Journal of medical internet research, Vol 19, No 5p.176 https://doi.org/10.2196/jmir.7332

[49] Achenbach, T. M. (2003). Manual for the Youth Self-Report and 1991 Profile. Burlington, VT: University of Vermont, Department of Psychiatry

[50] Economou,M., Angelopoulos, N(1989) Dysthymic Symptoms, Hostility and Scholastic Achievement in a Group of High-school Students Educational Psychology. Volume 9, Issue 4, pp 136-147

[51] Kaltiala-Heino, R., Rimpelä, M., Rantanen, P,(2000) Bullying at school—an indicator of adolescents at risk for mental disorders, Journal of Adolescence, Volume 23, Issue 6, pp 661-674 https://doi.org/10.1006/jado.2000.0351

[52] Kovacs, M., \& Goldston, D. (1991). Cognitive and social cognitive development of depressed children and adolescents. Journal of the American Academy of Child \& Adolescent Psychiatry, 30(3), 388-392. https://doi.org/10.1097/00004583-199105000-00006

[53] Spence,S.H, Sheffield, J.K.,Donovan, C.L.(2003) Preventing Adolescent Depression: An Evaluation of the Problem Solving for Life Program, Journal of Consulting and Clinical Psychology, Vol. 71, No. 1, 3-13 https://doi.org/10.1037/0022-006X.71.1.3

[54] Shochet, I. M., Dadds, M. R., Holland, D., Whitefield, K., Harnett, P. H.,\& Osgarby, S. (2001). The efficacy of a universal school-based programto prevent adolescent depression. Journal of Clinical Child Psychology, 30, 303-315 https://doi.org/10.1207/S153 74424JCCP3003 3

[55] Segrin.C.,Flora,J.(1998) Depression and verbal behavior in conversations with friends and strangers, Journal of Language and Social Psychology, Vol 17, Issue 4, pp 492-503 https://doi.org/10.1177/0261927X980174005

[56] Mark,D.,Kern,L.(2014) Increasing Induction-Level Teachers' Positive-to-Negative Communication Ratio and Use of Behavior-Specific Praise Through Emailed Performance Feedback and Its Effect on Students' Task Engagement Journal of Positive Behavior Interventions 16: 219-233 https://doi.org/10.1177/1098300713492856

\section{Authors}

Agathi Stathopoulou is a teacher in Secondary Education with a specialization in Greek philology. She holds a PhD in Special Education. She has taken part in research projects and seminars. At the current period is serving as a special educator at the Center for Diagnosis, Differentiation and Support, where pupils with special educational needs are assessed, in the B area of Athens. She is also a scientific associate at Net Media Lab, Brain \& Mind R\&D of N.C.S.R. 'Demokritos'. 
Zoe Karabatzaki is a School Advisor at the 21st Preschool Educational Region of Athens. She holds a Ph.D. on Educational Sciences (Special Education). She has participated in many educational seminars and conferences as a keynote speaker and as instructor. Furthermore, she has taken part in research programs that were supported by many universities of Greece. She has written two books, chapters in collective volumes, articles in scientific journals and educational notes. She has taught at the Department of Special Education of UTH (University of Thessaly), at the Department of Education and Early Childhood of UOA and the Department of Greek Literary of Democritus University of Thrace. She is also a scientific associate at Net Media Lab, Brain \& Mind R\&D of N.C.S.R. 'Demokritos'.

Georgia Kokkalia (MSc in Specific Learning Difficulties) is a Special Education Teaching Professional and Phd Candidate in University of Athens. She has participated in various research projects regarding the use of Information and Communication Technologies (ICTs) in Special Education and in Kindergarten.

Eleni Dimitriou (MSc in Special Needs and Inclusive Education) is a Special Education Teaching Professional in Secondary Education and a Phd Candidate, for the University of Athens. She is also a scientific associate at Net Media Lab, Brain \& Mind R\&D of N.C.S.R. 'Demokritos'. She has participated in various research projects in Special Education and as Rapporteur for the Seminar: "Special Education subjects with the support of the Technology".

Paraskevi Ioanna Loukeri (Msc Education Management and Leadership in the University of Southampton), is a Primary School Teacher and $\mathrm{PhD}$ candidate in the Kapodistrian University of Athens. She has publications on educational management and she is also a scientific associate at Net Media Lab, Brain \& Mind R\&D of N.C.S.R. 'Demokritos'.

Alexandra Economou is an assistant professor at the University of Athens in the department of Psychology. She teaches undergraduate and postgraduate neuropsychology and experimental psychology courses at the University of Athens in the Department of Psychology while her interests focus on cognitive and biological psychology. Dr. Economou is also vice-president of the Greek Aphasia Association.

Athanasios Drigas is a director of research at N.C.S.R. Demokritos. He is the Coordinator and founder of Net Media Lab, Brain \& Mind R\&D since 1996. From 1985 to 1999 he was the Operational manager of the Greek Academic network. He has been the Coordinator of Several International Projects, in the fields of ICTs, and eservices (e-learning, e-psychology, e-government, e-inclusion, e-culture etc). He has published more than 200 articles, 7 books, 25 educational CD-ROMs and several patents. He has been a member of several International committees for the design and coordination of Network and ICT activities and of international conferences and journals.

Article submitted 29 November 2017. Final acceptance 08 May 2018. Final version published as submitted by the authors. 